\title{
Molecular Mechanisms of Antipsychotic Drug-Induced Diabetes
}

\author{
Jiezhong Chen ${ }^{1,2}$, Xu-Feng Huang ${ }^{2,3}$, Renfu Shao ${ }^{4}$, Chen Chen ${ }^{1}$ and Chao Deng ${ }^{2,3 *}$ \\ ${ }^{1}$ School of Biomedical Sciences, The University of Queensland, St Lucia, QLD, Australia, ${ }^{2}$ School of Medicine, University of \\ Wollongong, Wollongong, NSW, Australia, ${ }^{3}$ Illawarra Health and Medical Research Institute, Wollongong, NSW, Australia, \\ ${ }^{4}$ Faculty of Science, Health, Education and Engineering, GeneCology Research Centre, University of the Sunshine Coast, \\ Maroochydore, QLD, Australia
}

Antipsychotic drugs (APDs) are widely prescribed to control various mental disorders. As mental disorders are chronic diseases, these drugs are often used over a life-time. However, APDs can cause serious glucometabolic side-effects including type 2 diabetes and hyperglycaemic emergency, leading to medication non-compliance. At present, there is no effective approach to overcome these side-effects. Understanding the mechanisms for APD-induced diabetes should be helpful in prevention and treatment

OPEN ACCESS

Edited by:

Miguel López,

Universidade de Santiago de

Compostela, Spain

Reviewed by:

Johan Anders Fernø, Haukeland University Hospital, Norway

Ismael González-García, Universidade de Santiago de

Compostela, Spain

*Correspondence:

Chao Deng

chao@uow.edu.au

Specialty section:

This article was submitted to Neuroendocrine Science,

a section of the journal

Frontiers in Neuroscience

Received: 28 August 2017 Accepted: 06 November 2017 Published: 21 November 2017

Citation:

Chen J, Huang X-F, Shao R, Chen C and Deng C (2017) Molecular Mechanisms of Antipsychotic

Drug-Induced Diabetes.

Front. Neurosci. 11:643. doi: 10.3389/fnins.2017.00643 of these side-effects of APDs and thus improve the clinical outcomes of APDs. In this review, the potential mechanisms for APD-induced diabetes are summarized so that novel approaches can be considered to relieve APD-induced diabetes. APD-induced diabetes could be mediated by multiple mechanisms: (1) APDs can inhibit the insulin signaling pathway in the target cells such as muscle cells, hepatocytes and adipocytes to cause insulin resistance; (2) APD-induced obesity can result in high levels of free fatty acids (FFA) and inflammation, which can also cause insulin resistance. (3) APDs can cause direct damage to $\beta$-cells, leading to dysfunction and apoptosis of $\beta$-cells. A recent theory considers that both $\beta$-cell damage and insulin resistance are necessary factors for the development of diabetes. In high-fat diet-induced diabetes, the compensatory ability of $\beta$-cells is gradually damaged, while APDs cause direct $\beta$-cell damage, accounting for the severe form of APD-induced diabetes. Based on these mechanisms, effective prevention of APD-induced diabetes may need an integrated approach to combat various effects of APDs on multiple pathways.

Keywords: antipsychotics, diabetes mellitus, metabolic disorders, insulin resistance, obesity, pancreatic beta cell, apoptosis

\section{INTRODUCTION}

Antipsychotic drugs (APDs) are widely prescribed to control schizophrenia and bipolar disorders, as well as other mental disorders including dementia, major depression, and even drug addiction (Fraguas et al., 2011; Leucht et al., 2013; Zhang J.-P. et al., 2013; Samara et al., 2016). Typical APDs (also called first generation APDs) such as chlorpromazine, perphenazine and haloperidol were introduced to clinics more than 60 years ago. Therapeutic effects of typical APDs are mediated largely through potent blockage of dopamine D2 receptors (Ginovart and Kapur, 2012), which also cause extra-pyramidal symptoms (EPS) side-effects (Stahl, 2003). Since the 1990s, a number of 
atypical APDs (also called 2nd generation APDs) including olanzapine, clozapine and risperidone have been approved by the FDA, and are now widely used as first line APDs due to their improved tolerability and reduced EPS compared with typical APDs (Leucht et al., 2009; Zhang J.-P. et al., 2013). In addition, clozapine has better outcomes in treatmentresistant schizophrenia (Lewis et al., 2006; Samara et al., 2016). Besides blockage of D2 receptors, atypical APDs target multiple neuroreceptors such as serotoninergic 5-HT2A/5HT2C, histaminergic $\mathrm{H} 1$ and muscarinic M3 receptors (Correll, 2010). Although typical APDs have been reported causing a certain degree of metabolic disorders, atypical APDs, particularly clozapine and olanzapine, can cause much worse metabolic sideeffects including body weight gain, obesity, hyperlipidaemia, insulin resistance, hyperglycaemia and diabetes (Foley and Morley, 2011; De Hert et al., 2012; Deng, 2013; Lipscombe et al., 2014; Stubbs et al., 2015). Since psychiatric patients often face chronic and even life-time APD treatment, these side-effects are major considerations in APD medication (De Hert et al., 2012; Deng, 2013). Schizophrenia patients with APD treatment have 2.5 times higher risk of developing type 2 diabetes according to a recent meta-analysis which examined 25 studies, including 145,718 individuals with schizophrenia (22.5-54.4 years) and $4,343,407$ controls (Stubbs et al., 2015). It is noteworthy that over the last decade APD prescriptions in children and adolescents have sharply increased (Memarzia et al., 2014; Steinhausen, 2015). Recent studies have shown that APDs cause not only greater weight gain in children/adolescents than in adults but also significant risk of type 2 diabetes, which has been largely underestimated (Maayan and Correll, 2011; Samaras et al., 2014; Pramyothin and Khaodhiar, 2015; Sohn et al., 2015). These severe side-effects have a devastating impact on life quality, and is a key risk for severe health complications, including cardiovascular disease, stroke, and premature death (Foley and Morley, 2011; Lin et al., 2014; Wu et al., 2015). Understanding how diabetes develops in patients treated with APDs and preventing APD-induced diabetes will improve medication compliance.

\section{ANTIPSYCHOTIC-INDUCED DIABETES}

Diabetes is characterized by hyperglycaemia (fasting plasma glucose $\geq 126 \mathrm{mg} / \mathrm{dL}$ [ $7 \mathrm{mmol} / \mathrm{L}]$ ) due to insufficient insulin production or insulin resistance (Kahn et al., 2014). Insulin is well known to promote glucose metabolism to produce energy. Diabetes is commonly classified into two types; type 1 is due to auto-immune damage to pancreatic $\beta$-cells, leading to a complete deficiency of insulin; type 2 is caused by insulin resistance, i.e., the cells do not respond to insulin stimulation, as well as $\beta$-cell dysfunction (Kahn et al., 2014). There is a chronic development from insulin resistance to diabetes. In the case of insulin resistance, insulin secretion from $\beta$-cells can increase 4 -fold while $\beta$-cell mass can increase 2-fold (Kahn et al., 2006). Therefore, blood glucose levels can still be maintained at normal levels, however, if $\beta$-cells fail to increase insulin secretion, diabetes will occur.
APDs have been shown to cause both diabetes and hyperglycaemic emergencies. Chronic administration of APDs is known to cause diabetes, which has been demonstrated in both epidemiological investigations in patients and in animal studies (Boyda et al., 2010a; Sohn et al., 2015; Stubbs et al., 2015). A recent study of 307 patients with psychotic illnesses showed that olanzapine caused type 2 diabetes (17\%), obesity (48\%), dyslipidaemia (35\%) and hypertension (32\%) with mean treatment duration of 7.6 years, while other APDs also induced similar side-effects (Reed et al., 2014). Another study has shown that APDs caused 37\% prediabetes and 10\% diabetes (Manu et al., 2012). Furthermore, the European First-Episode Schizophrenia Trial (EUFEST) reported a $20-30 \%$ incidence rate of hyperglycemia after 1 year of treatment with olanzapine, quetiapine and ziprasidone, but no significant differences between these APDs (Fleischhacker et al., 2013). Comparison of 28,858 APD users with 14,429 controls showed that the risk of diabetes increased 3-fold in children and adolescents treated with APDs (Bobo et al., 2013). This APD-induced diabetes has been confirmed in animal models; olanzapine and clozapine have been shown to decrease the plasma level of insulin and to cause hyperglycaemia and insulin resistance in rats (Chintoh et al., 2009; Boyda et al., 2010a; Liu et al., 2017).

The major complication of diabetes is heart disease. APDs significantly increased acute myocardial infarction with adjusted odds ratio of the risk $2.52(95 \% \mathrm{CI}=2.37-2.68)$ (Lin et al., 2014). Citrome et al. examined diabetes and cardiovascular disease incidence in a large number of patients who used APDs including aripiprazole, olanzapine, risperidone, quetiapine, and ziprasidone (Citrome et al., 2013). It was found that these drugs caused diabetes at similar rates but olanzapine, risperidone and quetiapine caused more cases of cardiovascular disease than aripiprazole and ziprasidone (Citrome et al., 2013).

Recent attention has also been focused on APD-induced hyperglycaemic emergencies. Patients treated with atypical APDs have $\sim 10$ times higher risk in developing diabetic ketoacidosis (Polcwiartek et al., 2016). Lipscombe and colleagues conducted a multicenter retrospective cohort study including 725,489 patients to investigate hyperglycaemic emergencies (hyperglycaemia, diabetic ketoacidosis, hyperosmolar hyperglycaemic state) experienced by new users of risperidone, olanzapine, and other typical and atypical APDs (Lipscombe et al., 2014). The results showed that hyperglycaemic emergencies were 1 per 1,000 persons in patients aged 18-65 and 2 per 1,000 persons in those older than 65 . The events were much more frequent in patients with pre-existing diabetes (6-12 per 1,000 persons) (Lipscombe et al., 2014). It was similar in the risk of hyperglycaemic emergencies with initiation of olanzapine vs. risperidone.

In brief, both clinical and animal studies have shown that APDs can cause serious glucometabolic side-effects including hyperglycaemic emergency, insulin resistance, hyperglycaemia and type 2 diabetes, which is a major risk for cardiovascular disease and premature death. It is worth to note that the risk of type 2 diabetes in children and youths treated with APDs has been underestimated (Samaras et al., 2014). Understanding the underlying mechanisms will be important for preventing 
and treating these side-effects and thus improving the clinical outcomes of APDs.

\section{MECHANISMS FOR ANTIPSYCHOTIC-INDUCED DIABETES}

Over the past 10 years, a number of studies have aimed to explore the potential mechanisms underlying APD-induced diabetes. Based on recent progress, we summarized the findings into three molecular mechanisms for explaining APD-induced diabetes: (1) insulin resistance due to the direct effect of APDs, (2) APDcaused insulin resistance through obesity, and (3) APD-induced $\beta$-cell dysfunction and apoptosis.

\section{Mechanism 1: Insulin Resistance Due to Direct Effect of Antipsychotics}

Insulin, secreted by pancreatic $\beta$-cells, is the key hormone in promotion of glucose metabolism (Kahn et al., 2014). It increases the uptake of glucose by cells and thus maintains the homeostasis of blood glucose levels. Insulin resistance refers to the situation where the target cells lose response to insulin stimulation and thus reduce glucose uptake (Kahn et al., 2014). Increased blood glucose level are mainly caused by insulin resistance in the skeletal muscles, and also in the hepatic, renal and adipose tissue (Kahn et al., 2014). Of these, the main site for glucose utilization is muscle tissue, and represents $\sim 80 \%$ of glucose consumption (Fujii et al., 2005).

APD-induced insulin resistance could be independent of weight gain and increased food intake. It has been reported that, in patients within 3 months after initiation or switch to atypical APDs, new-onset gluco-metabolic abnormalities and diabetes was not associated with weight change and BMI (van Winkel et al., 2008). A recent study has shown that a single administration of olanzapine caused glucose metabolism change independent of obesity in healthy human subjects (Hahn et al., 2013). Aripiprazole has been shown to induce insulin resistance with metabolic changes where there is no weight gain or increase in food intake (Teff et al., 2013). Boyda et al. examined the acute effects $(60,180$, or $360 \mathrm{~min})$ of olanzapine, clozapine, risperidone and haloperidol on insulin resistance in rats at both low and high concentrations of clozapine $(2 \mathrm{mg} / \mathrm{kg} ; 20$ $\mathrm{mg} / \mathrm{kg})$, olanzapine $(1.5 \mathrm{mg} / \mathrm{kg}$ vs. $15 \mathrm{mg} / \mathrm{kg})$, risperidone $(0.5$ $\mathrm{mg} / \mathrm{kg}$ vs. $2.5 \mathrm{mg} / \mathrm{kg}$ ) and haloperidol $(0.1 \mathrm{mg} / \mathrm{kg}$ vs. $1.0 \mathrm{mg} / \mathrm{kg})$ (Boyda et al., 2010b). Insulin resistance was evaluated through HOMA-IR (homeostasis model assessment index for insulin resistance) values in fasted rats and glucose clearance during a glucose tolerance test. Both olanzapine and clozapine produced significant dose and time dependent effects on fasting plasma glucose and insulin concentrations, HOMA-IR values, insulin resistance and glucose intolerance (Boyda et al., 2010b; Liu et al., 2017). However, risperidone and haloperidol also caused significant increases in fasting glucose and/or insulin levels at the high dose, 60 min post-drug administration (Boyda et al., 2010b).

Insulin plays an important role in glucose consumable cells via the phosphoinositide 3-kinase (PI3K)/protein kinase $\mathrm{B}$ ( $\mathrm{PKB}$, also known as Akt) pathway (Figure 1). Insulin can bind to insulin receptors, leading to receptor autophosphorylation which in turn activates receptor tyrosine kinases that phosphorylate insulin receptor substrates (IRSs) including IRS1, IRS2, IRS3, IRS4, Gab1 (a member of the IRS1-like multisubstrate docking protein family) and Shc protein (Boucher et al., 2014). Phosphorylated IRSs activate PI3K by binding to its regulatory subunit via Src homology 2 ( $\mathrm{SH} 2$ ) domains, increasing the conversion of phosphatidylinositol (3,4)-bisphosphate (PIP2) into phosphatidylinositol $(3,4,5)$-trisphosphate (PIP3). PIP3 can increase the activities of 3-phosphoinositide-dependent protein kinases 1/2 (PDK1/2). PIP3 also binds to Akt and this leads to translocation of Akt to the membrane, where Akt is phosphorylated by PDK1/2 and mammalian target of rapamycin complex 2 (mTORC2) and activated. Activated Akt increases glucose transporter type 4 (GLUT4) translocation to the membrane to increase glucose uptake via Akt substrate AS160 (Boucher et al., 2014). There are three Akt isoforms; 1, 2, and 3. The isoform regulating GLUT4 is Akt 2. GLUT4 is mainly located in adipose tissue and striated muscle (skeletal and cardiac) as well as the neurons of the hippocampus. Inhibition of Akt by siRNA has been shown to abolish the effect of insulin on glucose transport in 3T3-L1 adipocytes (Jiang et al., 2003). Insulin action is impaired in the liver, adipose tissue and muscle of Akt2 knockout mice (Cho et al., 2001). There are also two natural negative regulators in the pathway: protein tyrosine phosphatases (PTPs) and phosphatise and tension homolog deleted on chromosome 10 (PTEN); PTPs dephosphorylate insulin receptors and PTEN converts PIP3 into PIP2 (Boucher et al., 2014). Deficiencies in PTPs and PTEN have been shown to increase insulin sensitivity in mice (Boucher et al., 2014).

In type 2 diabetes patients, it has been shown that insulininduced IRS-1 tyrosine phosphorylation, PI3K and Akt activities are decreased in skeletal muscles (Fröjdö et al., 2009). In adipose tissue, Akt2 phosphorylation is impaired in obese type 2 diabetes (Rondinone et al., 1999). In animal models, high fatdiet rats have defective insulin-induced GLUT-4 translocation in skeletal muscle which has been associated with decreased Akt activity (Tremblay et al., 2001). Therefore, abnormality of the insulin pathway in insulin target cells could be critical for the pathogenesis of diabetes.

APDs have been shown to inhibit Akt activity and thus cause insulin resistance in muscle cells (Engl et al., 2005). In L6 myotubes, olanzapine was shown to decrease glycogen content in a dose- and time- dependent fashion. Olanzapine diminished insulin-induced IRS-1 phosphorylation and abolished insulininduced pPI3K, pAkt, and pGSK-3, while amisulpride, which does not cause diabetes, did not result in the above changes, indicating the importance of the insulin pathway in APDinduced diabetes (Engl et al., 2005). Olanzapine has been found to attenuate phosphorylation of insulin-like growth factor receptor (IGF-R) and IRS1 stimulated by insulin in wild-type fibroblast cells (Alghamdi et al., 2014). The mechanism has been considered to be olanzapine-induced membrane associated mammalian neuraminidase-3 (Neu3) and Neu 1 sialidase activity reduction. Alghamdi reported that Neul and matrix metalloproteinase9 (MMP-9) could cross-talk in alliance with the neuromedin B G-protein coupled receptor (GPCR) to promote the insulin 


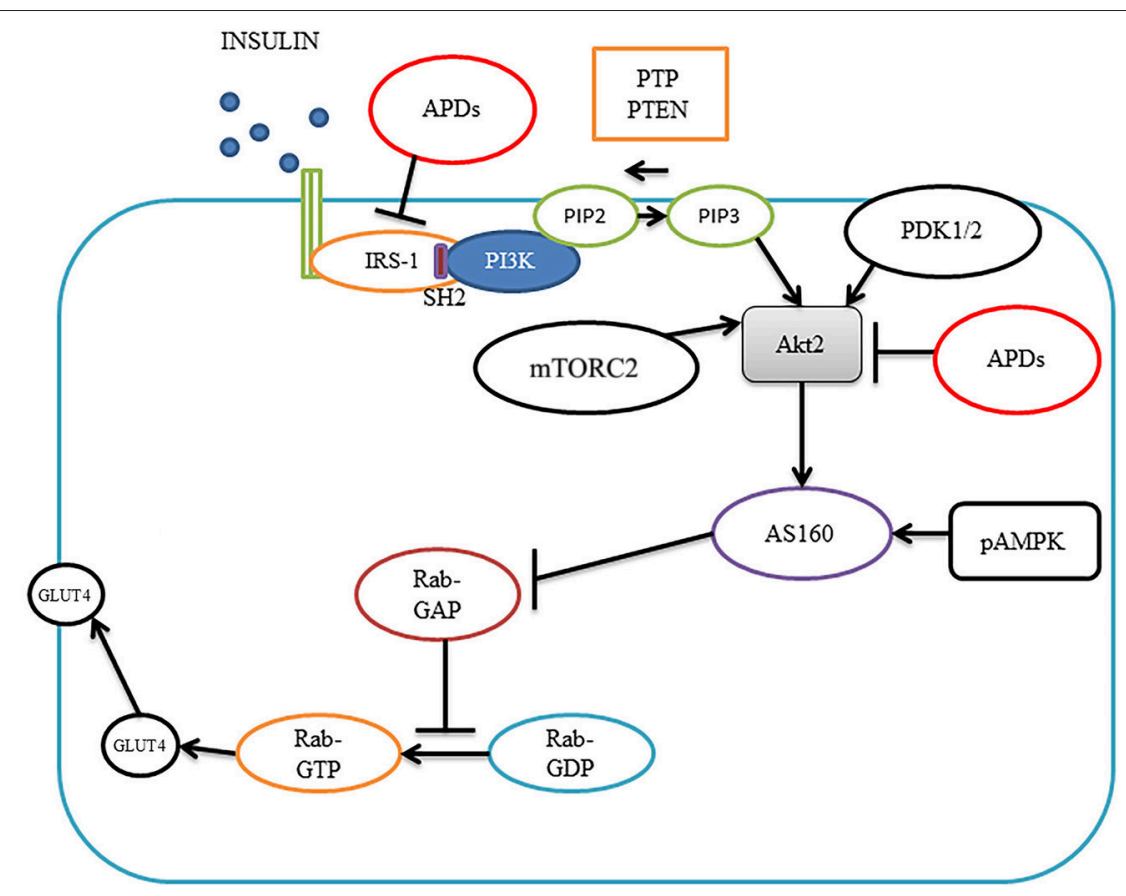

FIGURE 1 | Insulin signaling pathways and antipsychotic effects. Insulin binds to insulin receptors to activate IRS1, leading to activation of PI3K, which converts PIP2 into PIP3, PIP3 brings Akt2 on to the membrane where PDK1/2 and mTORC2 phosphorylate Akt2. Akt2 activates AS160, which blocks Rab-GAP, leading to increased Rab-GTP, causing translocation of GLUT4 to the membrane for glucose transportation. Antipsychotics can diminish insulin-induced IRS-1 phosphorylation and inhibit Akt activity causing insulin resistance. Akt2, protein kinase 2; pAMPK, phosphor-AMP-activated protein kinase; APDs, antipsychotic drugs; GLUT4; glucose transporter type 4; IRS1, insulin receptor substrate 1; PI3K, phosphoinositide 3-kinase; PIP2, phosphatidylinositol (3,4)-bisphosphate; PIP3, phosphatidylinositol $(3,4,5)$-trisphosphate; PDK1/2, phosphoinositide-dependent kinase-1; mTORC2 mammalian target of rapamycin complex 2 and SH2, Src homology 2.

signaling pathway (Alghamdi et al., 2014). Clozapine has been reported to reduce insulin-stimulated glucose uptake in PC12 and in L6 cells, which was companioned with 40\% decreased insulin effect on insulin receptor, $60 \%$ decrease in IRS1 tyrosine phosphorylation, and $40 \%$ decrease in insulin-stimulated Akt phosphorylation (Panariello et al., 2012). The inhibitory effect of APDs on Akt activity has also been reported in T-cells and glioblastoma cells (Shin et al., 2006; Chen M.-L. et al., 2011). However, the effects of APDs on the other elements of the insulin pathway such as PTPs and PTEN have not been studied and warrant further investigation.

\section{Mechanism 2: Antipsychotic-Caused Insulin Resistance through Obesity}

APDs are a well-known cause of obesity which is closely associated with diabetes. It has been repeatedly reported that APD-induced insulin resistance and diabetes are associated the increased weight gain, BMI and intra-abdominal adiposity, particularly in patients with chronic APD treatment (Bou Khalil, 2012; Manu et al., 2012). As many as 20-50\% of APD treated patients are obese and have diabetes (Deng, 2013). Animal experiments also demonstrated that APDs can cause obesity, although there are some limitations (Boyda et al., 2010a; WestonGreen et al., 2011; van der Zwaal et al., 2014). One limitation is a failure to induce weight gain by clozapine in rodents in the majority of studies, although clozapine has been well established to cause dyslipidaemia, hyperglycaemia and insulin resistance in rodents (Boyda et al., 2010a; Liu et al., 2017), which provides a model to investigate the direct effects of clozapine on these metabolic parameters in rats without weight gain (Cooper et al., 2008; Liu et al., 2017). However, a recent study has reported that chronic clozapine treatment induced weight gain and fasting glucose levels in male rats (von Wilmsdorff et al., 2013). The most successfully established rodent model for APD-induced weight gain/obesity is by olanzapine (Weston-Green et al., 2011; van der Zwaal et al., 2014; Lord et al., 2017). Other APDs such as risperidone, sulpiride, haloperidol, and chlorpromazine have also been established to cause some degree of weight gain in rats and mice (Boyda et al., 2010a; Lian et al., 2015). There is also a sexual dimorphism in the obesogenic response to APDs, which is particularly clear in rodent models with male rats repeatedly reported less sensitive to APD-induced weight gain than females (Minet-Ringuet et al., 2006; Weston-Green et al., 2010; von Wilmsdorff et al., 2013). Although sex differences are less established in humans, females have been often observed with higher risks for weight gain and other metabolic sideeffects (including increased insulin-resistance and higher plasma triglycerides) caused by APDs (Wu et al., 2007; Seeman, 2009; Weston-Green et al., 2010). Based on data from both clinical and animal studies, there are three stages in APD-caused obesity: during the first few months treatment in schizophrenia patients, APDs cause rapid weight gain (stage 1) followed by a steady 
weight gain for about 1 year (stage 2) to reach a plateau and then a stage (stage 3 ) for maintaining heavy weight (Zipursky et al., 2005; Pai et al., 2012; Deng, 2013). Similar developmental stages of APD-induced obesity have also been observed in rat models (Huang et al., 2006; He et al., 2014). Therefore, APD-caused obesity is a chronic process.

The mechanism for APD-caused obesity is considered to be increased appetite and food intake rather than decreased energy expenditure in the early stage of obesity development (Deng, 2013). APDs can act as an antagonist on serotonin 5-HT2C, histamine $\mathrm{H} 1$, and dopamine D2 receptors to increase appetite and thus increase food intake, leading to obesity (Figure 2; Matsui-Sakata et al., 2005; Han et al., 2008; Nasrallah, 2008; Kirk et al., 2009; Deng et al., 2010; Lian et al., 2016). It has been found that inhibition of 5-HT2C by olanzapine contributes to olanzapine-induced weight gain and hyperphagia in rodents (Kirk et al., 2009; Lord et al., 2017), while these effects were blunted in mice lacking 5-HT2C (htr2c-null mice) (Lord et al., 2017). 5-HT2C can promote anorexigenic proopiomelanocortin (POMC) neurons to decrease appetite (Lam et al., 2008, 2010; Lian et al., 2016). Indeed, olanzapine has been shown to decrease POMC expression in rats (Ferno et al., 2011; Weston-Green et al., 2012a; Lian et al., 2014a; Zhang et al., 2014a). MatsuiSakata showed that $\mathrm{H} 1$ receptor blockage is the main reason for APD-induced obesity (Matsui-Sakata et al., 2005). APDs block $\mathrm{H} 1$ receptors and thus activate hypothalamic 5' AMPactivated protein kinase (AMPK), which stimulates appetite in rats (Kim et al., 2007; Han et al., 2008; Deng et al., 2010; He et al., 2013). It is interesting that an histamine $\mathrm{H} 1$ agonist (2(3-trifluoromethylphenyl) histamine) is able to reverse increased hypothalamic AMPK activation and hyperphagia induced by olanzapine in rats (He et al., 2014). Fernø and colleagues have reported a decreased hypothalamic AMPK phosphorylation by subchronic olanzapine treatment and no effects after acute treatment of olanzapine or clozapine in rats (Ferno et al., 2011), however they measured AMPK phosphorylation $20 \mathrm{~h}$ after the final drug treatment that might explain their failures to detect the increased AMPK activation by APDs in this study. In fact, a further study by the same research group has proven the important role of hypothalamic AMPK activation in olanzapineinduced weight gain by means of adenovirus-mediated inhibition of AMPK in the arcuate nuclei of female rats with olanzapine depot exposure (Skrede et al., 2014). Furthermore, direct intracerebroventricular infusion of olanzapinehas been reported to induce hypothalamic AMPK activation and hepatic insulin resistance in rats (Martins et al., 2010). APDs have also been found to increase neuropeptide Y (NPY) expression (Lian et al., 2014a; Zhang et al., 2014a), which could be partially through blocking $\mathrm{H} 1$ receptors and reversed by $\mathrm{H} 1$ agonist (Lian et al., 2014a,b, 2016). The D2 receptor is associated with the reward system and thus appetite (Deng, 2013). APDs can bind and block D2 receptors to increase appetite (Nasrallah, 2008; Deng, 2013). Recently a study has shown that the gut microbiome plays an important role in APD-induced obesity in rats (Davey et al., 2013). In view of the importance of this microbiome in diet-induced obesity (Bäckhed et al., 2004, 2007; Turnbaugh et al., 2009), Davey et al. tested the role of this microbiome

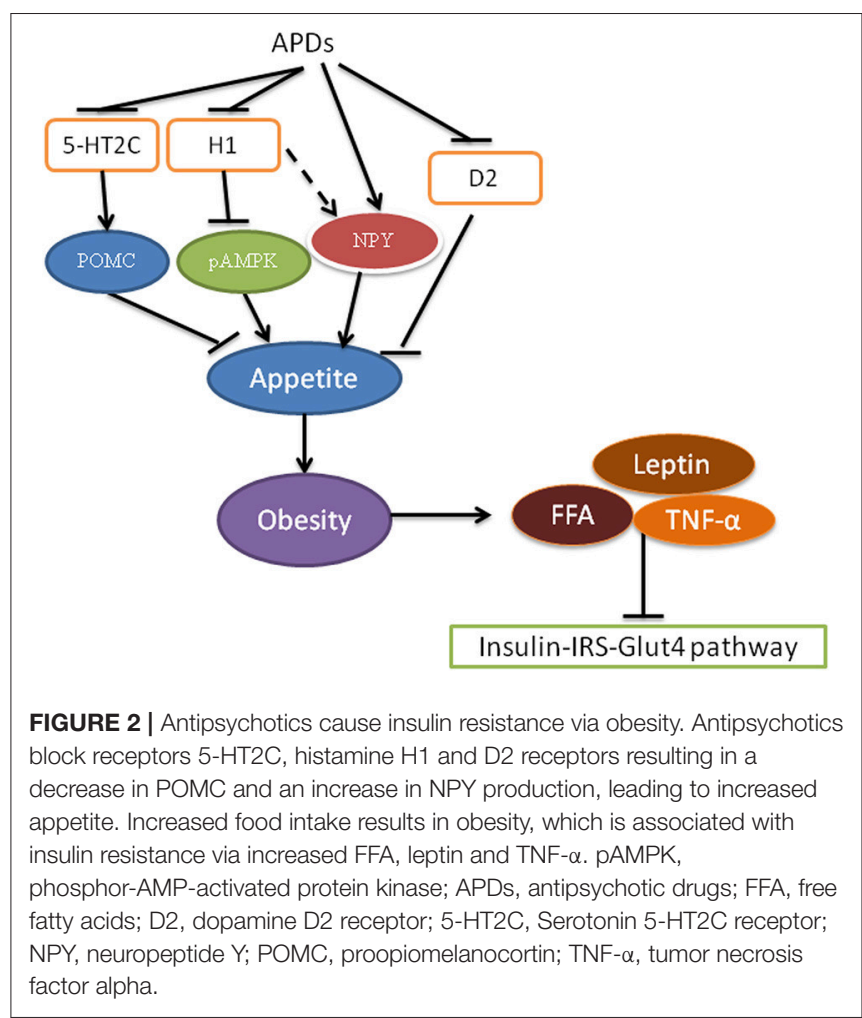

in olanzapine-induced obesity and found that use of antibiotics resulted in decreased fat accumulation in rats treated with olanzapine (Davey et al., 2013). Regarding to energy expenditure, similar to the sedative effects of APDs on humans, it has been widely reported that APDs such as olanzapine and risperidone decreased locomotor activities in both rats and mice (Fell et al., 2007; Cope et al., 2009; Weston-Green et al., 2011; Zhang et al., 2014b; Lian et al., 2015; Lord et al., 2017). Although a recent study found an increased heat production in mice treated with olanzapine (Lord et al., 2017), a previous study reported a decrease of metabolic rate in mice with olanzapine infusion $(8 \mathrm{mg} / \mathrm{kg} /$ day $)$ but not in mice with a lower dose $(4 \mathrm{mg} / \mathrm{kg} /$ day $)$ (Coccurello et al., 2009). Furthermore, a number of studies in rats reported that olanzapine reduced core body temperature or thermogenesis of brown adipose tissue (BAT) accompanied with decreased expression of functional thermogenic proteins, uncoupling protein1 (UCP1) and peroxisome proliferatoractivated receptor gamma coactivator- $1 \alpha$ (PGC- $1 \alpha)$ of BAT (Stefanidis et al., 2009; van der Zwaal et al., 2012; Zhang et al., 2014b). Therefore, further studies are necessary to clarify the effects of APDs on thermogenesis.

Obesity is closely related to diabetes through insulin resistance and inflammation (Kahn et al., 2014; Verma and Hussain, 2017). In obesity, blood insulin levels are increased. However, in obese rats, the efficacy of insulin to stimulate Akt2 activity decreases in the muscle and liver, suggesting insulin resistance in these tissue (Kim et al., 2000). In obesity, increased blood levels of free fatty acids (FFA), tumor necrosis factor alpha (TNF-alpha) and leptin have been demonstrated to contribute to the development of type 
2 diabetes (Verma and Hussain, 2017). Blood levels of FFA were increased in obesity due to an increased release from an increased size and number of adipocytes (Verma and Hussain, 2017). Increased FFA levels in turn inhibit insulin/IRS phosphorylation, leading to insulin resistance in insulin target cells such as skeletal muscle, the liver and endothelial cells (Kahn et al., 2006; Wilding, 2007). Decreased IRS phosphorylation causes decreased PI3K/Akt pathway activity and GLUT4 translocation (Wilding, 2007). Lowering the levels of FFA has been shown to increase insulin sensitivity in obese and non-obese diabetic subjects, indicating the important role of FFA in insulin resistance (Goodpaster and Coen, 2014). Exercise has been shown to reduce FFA and improve insulin sensitivity (Kwak, 2013; Malin et al., 2016).

Olanzapine has been shown to increase lipogenesis and thus increase FFA (Albaugh et al., 2011a). Recent studies showed that blood levels of FFA were significantly increased in rats after chronic administration of olanzapine (Davey et al., 2013; Liu et al., 2015, 2017). Jassim et al showed that a single injection of clozapine and olanzapine in rats increased serum FFA after 12$24 \mathrm{~h}$ (Jassim et al., 2012). A recent study in male rats showed that olanzapine could stimulate lipogenesis independent of weight gain, but with dosage-dependent effects (Ferno et al., 2015). All these studies support the view that APD-induced obesity could contribute to insulin resistance partially via increased blood levels of FFA.

TNF-alpha, which is increased in obesity, may also play a key role in the link between obesity and diabetes (Verma and Hussain, 2017). Both cell culture and animal studies have shown TNF-alpha to interfere with the insulin pathway causing insulin resistance (Nieto-Vazquez et al., 2008). Knockout of TNF-alpha decreased obesity-caused insulin resistance (Uysal et al., 1997). In addition, Interleukin 1 (IL-1), IL-6 and leptin are also increased in obesity and have been associated with insulin resistance (Verma and Hussain, 2017). Chronic treatment (46 days) with olanzapine has been reported to increase TNF alpha expression in adipose tissue and plasma and IL-1 expression in rat plasma (Victoriano et al., 2010). In addition, administration of olanzapine and other atypical APDs has been shown to increase blood levels of leptin and ghrelin, suggesting that leptin and ghrelin could also be a link between APD-induced obesity and diabetes (Jin et al., 2008; Albaugh et al., 2011b; Zhang Q. et al., 2013). As an adipocyte-derived hormone, adiponectin controls lipid and carbohydrate metabolism, in which a low adiponectin level is associated with obesity, insulin resistance and type 2 diabetes (Jin et al., 2008). Schizophrenia patients with metabolic disorders have been reported with a low adiponectin levels (Hanssens et al., 2008; Oriot et al., 2008; Chen P.-Y. et al., 2011; Sugai et al., 2012). Accumulated evidence has shown that treatment with atypical APDs clozapine and olanzapine decreases plasma adiponectin levels associated with weight gain, high fasting glucose, hypertriglyceridemia, insulin resistance induced by these drugs (Hanssens et al., 2008; Bai et al., 2009; Wampers et al., 2012; Klemettila et al., 2014), although it should be noted that some atypical APDs (e.g., risperidone) did not affect adiponectin levels (Murashita et al., 2007; Wampers et al., 2012).

\section{Mechanism 3: Antipsychotic-Induced $\beta$-Cell Dysfunction and Apoptosis}

Recent studies have paid attention to the role of $\beta$-cells in APD-induced diabetes. Pancreatic $\beta$-cells are the only type of cells that secrete insulin. The pathogenesis of diabetes involves the altered mass and function of $\beta$-cells (Kahn et al., 2014). It has been recognized that $\beta$-cell damage is necessary for the pathogenesis of type 2 diabetes (Kahn et al., 2014). Insulin resistance alone is regarded as insufficient to cause diabetes. According to $\beta$-cell damage, the development of diabetes is classified into five stages (Weir and Bonner-Weir, 2004). Stage 1 is compensation in which insulin secretion is increased and blood glucose levels are maintained at normal levels. Stage 2 is characterized by the mild rise of blood glucose levels to 5.0-6.5 $\mathrm{mmol} / \mathrm{L}$ in which there are loss of $\beta$-cell mass and function. Stage 3 is early decompensation, in which maintenance of a normal range of blood glucose levels does not occur due to the inability of damaged $\beta$-cells to secrete insulin. Stage 4 is characterized by stable decompensation and significant $\beta$-cell damage. Stage 5 is major decompensation where profound reduction of $\beta$-cell mass and ketosis occurs. Therefore, protection of $\beta$-cells and promotion of human $\beta$-cell proliferation have been investigated in preclinical models to improve diabetes (Xiao et al., 2014; Shirakawa and Kulkarni, 2016).

APDs can cause $\beta$-cell damage directly and indirectly. The first evidence for APD-induced $\beta$-cell damage was from the studies of olanzapine-induced insulin resistance in canine models in comparison with a high-fat diet (Ader et al., 2005; Bergman and Ader, 2005). It was found that there was no expected $\beta$-cell compensation for olanzapine-induced insulin resistance (Ader et al., 2005; Bergman and Ader, 2005). This is different from insulin resistance induced by a high-fat diet which confers $\beta$ cell compensation, suggesting that olanzapine can cause $\beta$-cell damage. Chintoh et al also demonstrated that APDs caused $\beta$-cell damage in a rat model (Chintoh et al., 2009). It was found that acute treatment with clozapine and olanzapine at the dosages of 10 and $3 \mathrm{mg} / \mathrm{kg}$ respectively produced insulin resistance evidenced by decreased glucose infusion, increased hepatic glucose production and decreased peripheral glucose utilization (Chintoh et al., 2009). Clozapine and olanzapine also decreased $\beta$-cell insulin secretion under hyperglycaemic clamp, indicating that direct $\beta$-cell damage accompanied clozapine- and olanzapine- induced insulin resistance. Olanzapine and clozapine have been shown to decrease insulin secretion in islet $\beta$-cells (Johnson et al., 2005; Weston-Green et al., 2013). In isolated rat islets, olanzapine and clozapine inhibited cholinergic-glucose induced insulin secretion but risperidone and ziprasidone did not (Johnson et al., 2005). These results may account for the fact that diabetes is common in patients treated with clozapine and olanzapine as $\beta$-cell damage can accelerate the development of diabetes from insulin resistance.

Studies have now shown various mechanisms for APD-caused $\beta$-cell dysfunction (Figure 3). APDs can act on several $\beta$-cell receptors to cause decreased insulin secretion. Binding experiments showed that APDs can bind to various receptors including dopaminergic, histaminergic, serotonergic, adrenergic 


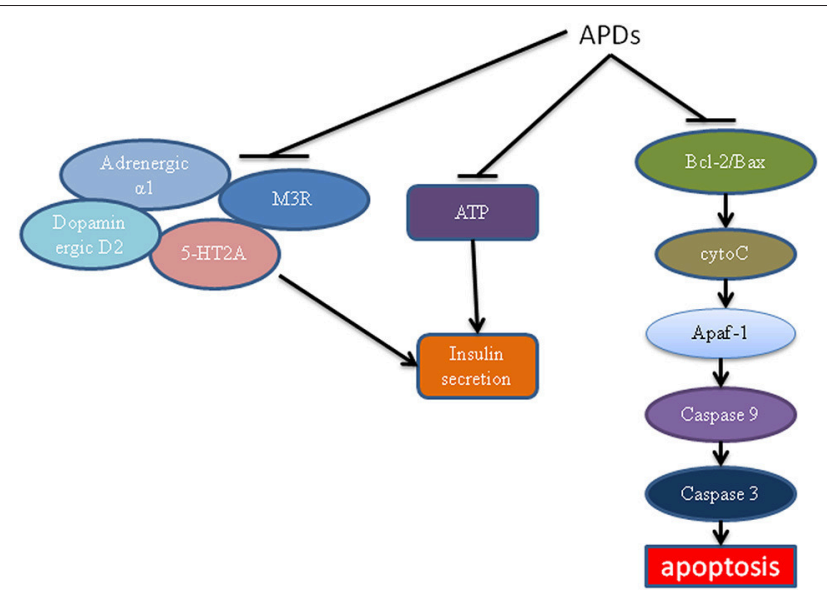

FIGURE 3 | The effects of antipsychotics on $\beta$-cells. Antipsychotics can block ATP and M3, adrenergic $\alpha 1$ and $5-\mathrm{H}$ T2A receptor-mediated insulin secretion. APDs act on the mitochondrial apoptotic pathway, leading to decreased $\mathrm{Bcl}-2$ ratio, increased cytochrome $c$ release, Apaf/caspase activation and apoptosis. APDs, antipsychotic drugs; ATP, adenosine triphosphate; M3R, muscarinic M3 receptor; Apaf, apoptotic protease activating factor.

and muscarinic receptors (Guenette et al., 2013). It is known that blockade of the 5-HT2A and muscarinic M3 receptors weakens insulin response to glucose challenge, whereas antagonism at the dopamine D2 receptor increases insulin secretion (Rubí et al., 2005; Hahn et al., 2011; Weston-Green et al., 2013). Guenette et al. used a series of antagonists to screen their effects on insulin secretion including prazosin (a selective adrenergic $\alpha 1$ antagonist), idazoxan (a selective adrenergic $\alpha 2$ antagonist), SB242084 (a selective 5-HT2C antagonist), WAY100635 (a selective 5HT1A antagonist), and MDL100907 (a selective 5-HT2A antagonist). It was found that only prazosin and MDL100907 were associated with decreased insulin secretion (Guenette et al., 2013). Olanzapine and clozapine may bind to these receptors, blocking them to stimulate insulin secretion (Guenette et al., 2013). Interestingly, antagonist affinity with M3 has been demonstrated to be a main indicator of diabetes induced by APDs (Silvestre and Prous, 2005). APDs which have high binding affinity with M3 receptors, such as olanzapine and clozapine, have been shown to decrease insulin secretion (Johnson et al., 2005; Weston-Green et al., 2012b), providing clear evidence for the important role of M3 receptors in the direct effect of APDs on $\beta$-cells (Deng, 2013; Weston-Green et al., 2013).

APDs have also been linked to an increase in apoptosis of $\beta$ cells, leading to lower mass and thus decreased insulin secretion. Ozasa et al. demonstrated that APDs can act directly on $\beta$-cells to cause apoptosis (Ozasa et al., 2013). Therefore, $\beta$-cell mass is decreased, leading to decreased insulin secretion. Clozapine has also been shown to damage $\beta$-cells to cause diabetes (Best et al., 2005). The effect of APD-induced $\beta$-cell damage may be mediated by the mitochondrial apoptotic pathway (Figure 3). This pathway was regulated by proapoptotic proteins such as Bak, Bax, Bid, Bim, Bcl-associated death promoter (BAD), Noxa, and PUMA (Chen et al., 2013). It was also regulated by antiapoptotic proteins such as Bcl-2, Bcl-xL, Bcl-w, Mcl-1, and A1 (Chen et al., 2013). A changed ratio of proapoptotic proteins to antiapoptotic proteins can lead to the release of cytochrome c, resulting in promotion of the formation of active apaf (apoptotic protease activating factor)/caspase-9 complex (apoptosome), leading to caspase-3 activation and apoptosis. Contreras-Shannon et al. showed that clozapine caused mitochondrial damage in several types of insulin responding cells, including cultured mouse myoblasts (C2C12), adipocytes (3T3-L1), hepatocytes (FL83B), and monocytes (RAW 264.7) (Contreras-Shannon et al., 2013). A proteomic study has also shown that olanzapine and clozapine cause dramatic mitochondrial protein changes in the hippocampus of rats (Ji et al., 2009). Although neither study was carried out in $\beta$-cells, they showed APDs had a direct effect on the mitochondrial apoptotic pathway. The effect of APDs on $\beta$ cell mitochondria warrants detailed investigation. It may reveal a major mechanism for APD-induced diabetes.

Decreased insulin secretion caused by APDs could also be mediated by ATP. ATP is mainly produced in mitochondria and known to regulate insulin secretion (Seino, 2012). In physiological condition, glucose metabolism increases ATP production. Accumulation of ATP in $\beta$-cells leads to closing of the $\mathrm{K}_{\text {ATP }}$ channels and opening of the voltage-dependent $\mathrm{Ca}^{2+}$ channels, resulting in $\mathrm{Ca}^{2+}$ influx to trigger insulin secretion (Seino, 2012). It has been shown that treatment of insulin responsive cells with clozapine reduced ATP production. It is possible that APDs also affect ATP production in $\beta$-cells.

In summary, APDs can affect the $\beta$-cell insulin secretion function. This may be mediated by several receptors particularly the M3 receptors. APDs could also cause $\beta$-cell apoptosis and decrease production of ATP. Further detailed studies will be helpful to elucidate these important mechanisms.

\section{PREVENTIVE AND THERAPEUTIC IMPLICATIONS}

As discussed above, multiple mechanisms are involved in APDinduced diabetes including increased appetite, insulin resistance and $\beta$-cell damage. Prevention of these changes caused by APDs could be critical for medication compliance and improving clinical outcomes. To date, dozens of drugs have been trialed with some success in partly ameliorating antipsychotic-induced metabolic side-effects. Amantadine, metformin, reboxetine, sibutramine and topiramate have been shown to be effective in reducing $\mathrm{APD}$-induced weight gain in Baptista et al's examination of 25 pharmacologic weight loss intervention trials ( $n=1,221)$ (Baptista et al., 2008). Metformin was demonstrated to have the most promising effects on weight loss, followed by d-fenfluramine, sibutramine, topiramate, and reboxetine, in a meta-analysis of 32 placebo-controlled pharmacologic intervention trials involving 1,482 subjects (Maayan et al., 2010). Therefore, these drugs could ameliorate APD-induced insulin resistance via reducing obesity. Furthermore, the meta-analysis also showed that metformin and rosiglitazone (two antidiabetic drugs) can decrease insulin levels and insulin resistance (assessed using HOMA-IR) in patients treated with atypical APDs, 
even though they have no effects on fasting glucose levels (Maayan et al., 2010). However, in two studies, metformin was found to decrease fasting glucose along with decreased insulin and HOMA-IR in chronic schizophrenia patients treated with olanzapine (Baptista et al., 2006; Chen et al., 2008). In animal experiments, metformin and glyburide have been shown to reduce olanzapine-caused hyperglycaemia (Boyda et al., 2014). These results suggest that these antidiabetic drugs may directly ameliorate insulin resistance. Although metformin outperformed other agents, the current evidence is still too limited to support it as a regular adjunctive medication to control antipsychoticinduced weight gain and metabolic abnormalities (Maayan et al., 2010). Recently, a 16 weeks randomized clinical trial examined the effects of liraglutide (a glucagon-like peptide-1 [GLP-1] receptor agonist) used in conjunction with clozapine or olanzapine treatment on prediabetes and overweight/obesity in patients with schizophrenia spectrum disorders (Larsen et al., 2017). In the patients with liraglutide co-treatment, glucose tolerance was significantly improved, and particularly $63.8 \%$ prediabetic patients developed normal glucose tolerance. In addition, liraglutide induced weight loss and reduction in a number of cardiometabolic parameters including waist circumference, systolic blood pressure, visceral fat and lowdensity lipoprotein (Larsen et al., 2017).

Based on the key roles of histamine $\mathrm{H1}$ and 5-HT2C antagonisms in APD-induced weight gain, a number of animal and/or clinical trials targeted at these receptors have be examined recently. It has been shown that co-treatment with betahistine (an $\mathrm{H} 1$ agonist and $\mathrm{H} 3$ antagonist) could partially reduce olanzapine-induced weight gain in both schizophrenia patients and animal models (Deng et al., 2012; Poyurovsky et al., 2013; Lian et al., 2014a,b, 2016). Betahistine co-treatment can also ameliorate the increased triglyceride accumulation and non-esterified fatty acids caused by olanzapine via modulating AMPK-SREBP-1 and PPAR $\alpha$-dependent pathways (Liu et al., 2015). A recent animal trial found that lorcaserin (a 5-HT2Cspecific agonist) could not only partially reduced olanzapineinduced food intake and weight gain, but also improved glucose tolerance in female mice (Lord et al., 2017). In future, the major effort could be the elucidation of the mechanisms for APDinduced diabetes, particularly APD-induced $\beta$-cell damage. It is only the beginning to realize the important role of $\beta$-cells

\section{REFERENCES}

Ader, M., Kim, S. P., Catalano, K. J., Ionut, V., Hucking, K., Richey, J. M., et al. (2005). Metabolic dysregulation with atypical antipsychotics occurs in the absence of underlying disease a placebo-controlled study of olanzapine and risperidone in dogs. Diabetes 54, 862-871. doi: 10.2337/diabetes.54.3.862

Albaugh, V. L., Judson, J. G., She, P., Lang, C. H., Maresca, K. P., Joyal, J. L., et al. (2011a). Olanzapine promotes fat accumulation in male rats by decreasing physical activity, repartitioning energy and increasing adipose tissue lipogenesis while impairing lipolysis. Mol. Psychiatry 16, 569-581. doi: 10.1038/mp.2010.33

Albaugh, V. L., Singareddy, R., Mauger, D., and Lynch, C. J. (2011b). A double blind, placebo-controlled, randomized crossover study of the acute metabolic effects of olanzapine in healthy volunteers. PLoS ONE 6:e22662. doi: 10.1371/journal.pone.0022662 in APD-induced diabetes. Since APDs may decrease insulin secretion through blocking M3 receptors on $\beta$-cells (Johnson et al., 2005; Weston-Green et al., 2013), it is worth to trial whether a specific M3 agonist could mitigate APD-induced diabetes. Drugs or phytochemicals that can protect $\beta$-cells may be used for the prevention of APD-induced diabetes. For example, resveratrol and curcumin have been demonstrated to be effective to protect $\beta$-cells in streptozotocin-induced damage (Su et al., 2006; Meghana et al., 2007; Palsamy and Subramanian, 2010), which may be used in APD-induced $\beta$-cell damage.

\section{CONCLUSIONS}

APDs are associated with diabetes and hyperglycaemic emergency. This could be mediated by multiple mechanisms. APDs can inhibit the insulin signaling pathway in insulin sensitive cells such as muscle cells, hepatocytes and adipocytes to cause insulin resistance. APD-induced obesity can result in high levels of FFA and inflammation, which can cause insulin resistance as well. More importantly, APDs can cause direct damage to $\beta$-cells. This accounts for the rapid development of diabetes and severe diabetic complications. As multiple mechanisms are involved in APD-induced diabetes, preventive and therapeutic approaches may need to combine agents counteracting different mechanisms. Among them prevention of $\beta$-cell damage is of particular importance as diabetes would not happen without $\beta$-cell damage.

\section{AUTHOR CONTRIBUTIONS}

JC and CD conceived and outlined the manuscript. JC wrote the first draft of the manuscript. CD, X-FH, RS, and CC contributed to manuscript writing, editing, synthesis of previous literature.

\section{FUNDING}

This study was supported by a Project grant (APP1044624) from the National Health and Medical Research Council (NHMRC), Australia to $\mathrm{CD}$ and X-FH. The funding organization did not play a role in the design and conduct of the study. The authors have no conflicts of interest. Szewczuk, M. R. (2014). A novel insulin receptor-signaling platform and its link to insulin resistance and type 2 diabetes. Cell. Signal. 26, 1355-1368. doi: 10.1016/j.cellsig.2014.02.015

Bäckhed, F., Ding, H., Wang, T., Hooper, L. V., Koh, G. Y., Nagy, A., et al. (2004). The gut microbiota as an environmental factor that regulates fat storage. Proc. Natl. Acad. Sci. U.S.A. 101, 15718-15723. doi: 10.1073/pnas.0407076101

Bäckhed, F., Manchester, J. K., Semenkovich, C. F., and Gordon, J. I. (2007). Mechanisms underlying the resistance to diet-induced obesity in germ-free mice. Proc. Natl. Acad. Sci. U.S.A. 104, 979-984. doi: 10.1073/pnas.0605374104

Bai, Y. M., Chen, T. T., Yang, W.-S., Chi, Y.-C., Lin, C.-C., Liou, Y.-J., et al. (2009). Association of adiponectin and metabolic syndrome among patients taking atypical antipsychotics for schizophrenia: a cohort study. Schizophr. Res. 111, 1-8. doi: 10.1016/j.schres.2009.03.014 
Baptista, T., ElFakih, Y., Uzcategui, E., Sandia, I., Talamo, E., Araujo de Baptista, E., et al. (2008). Pharmacological management of atypical antipsychotic-induced weight gain. CNS Drugs 22, 477-495. doi: 10.2165/00023210-200822060-00003

Baptista, T., Martínez, J., Lacruz, A., Rangel, N., Beaulieu, S., Serrano, A., et al. (2006). Metformin for prevention of weight gain and insulin resistance with olanzapine: a double-blind placebo-controlled trial. Can. J. Psychiatry 51, 192-196. doi: 10.1177/070674370605100310

Bergman, R. N., and Ader, M. (2005). Atypical antipsychotics and glucose homeostasis. J. Clin. Psychiatry 66, 504-514. doi: 10.4088/JCP.v66n0414

Best, L., Yates, A. P., and Reynolds, G. P. (2005). Actions of antipsychotic drugs on pancreatic $\beta$-cell function: contrasting effects of clozapine and haloperidol. J. Psychopharmacol. 19, 597-601. doi: 10.1177/0269881105056641

Bobo, W. V., Cooper, W. O., Stein, C. M., Olfson, M., Graham, D., Daugherty, J., et al. (2013). Antipsychotics and the risk of type 2 diabetes mellitus in children and youth. JAMA Psychiatry 70, 1067-1075. doi: 10.1001/jamapsychiatry.2013.2053

Boucher, J., Kleinridders, A., and Kahn, C. R. (2014). Insulin receptor signaling in normal and insulin-resistant states. Cold Spring Harb. Perspect. Biol. 6:a009191. doi: 10.1101/cshperspect.a009191

Bou Khalil, R. (2012). Atypical antipsychotic drugs, schizophrenia, and metabolic syndrome in non-Euro-American societies. Clin. Neuropharmacol. 35, 141-147. doi: 10.1097/WNF.0b013e31824d5288

Boyda, H. N., Procyshyn, R. M., Asiri, Y., Wu, C., Wang, C. K., Lo, R., et al. (2014). Antidiabetic-drug combination treatment for glucose intolerance in adult female rats treated acutely with olanzapine. Progr. Neuro-Psychopharmacol. Biol. Psychiatry 48, 170-176. doi: 10.1016/j.pnpbp.2013.10.006

Boyda, H. N., Tse, L., Procyshyn, R. M., Honer, W. G., and Barr, A. M. (2010a). Preclinical models of antipsychotic drug-induced metabolic side effects. Trends Pharmacol. Sci. 31, 484-497. doi: 10.1016/j.tips.2010. 07.002

Boyda, H. N., Tse, L., Procyshyn, R. M., Wong, D., Wu, T. K., Pang, C. C., et al. (2010b). A parametric study of the acute effects of antipsychotic drugs on glucose sensitivity in an animal model. Prog. Neuro-Psychopharmacol. Biol. Psychiatry 34, 945-954. doi: 10.1016/j.pnpbp.2010.04.024

Chen, C.-H., Chiu, C.-C., Huang, M.-C., Wu, T.-H., Liu, H.-C., and Lu, M.L. (2008). Metformin for metabolic dysregulation in schizophrenic patients treated with olanzapine. Prog. Neuro-Psychopharmacol. Biol. Psychiatry 32, 925-931. doi: 10.1016/j.pnpbp.2007.11.013

Chen, J., Shao, R., Zhang, X. D., and Chen, C. (2013). Applications of nanotechnology for melanoma treatment, diagnosis, and theranostics. Int. J. Nanomedicine 8, 2677-2688. doi: 10.2147/IJN.S45429

Chen, M.-L., Tsai, T.-C., Lin, Y.-Y., Tsai, Y.-M., Wang, L.-K., Lee, M.-C., et al. (2011). Antipsychotic drugs suppress the AKT/NF- $\mathrm{B}$ pathway and regulate the differentiation of T-cell subsets. Immunol. Lett. 140, 81-91. doi: 10.1016/j.imlet.2011.06.011

Chen, P.-Y., Huang, M.-C., Chiu, C.-C., Liu, H.-C., Lu, M.-L., and Chen, C.H. (2011). Association of plasma retinol-binding protein-4, adiponectin, and high molecular weight adiponectin with metabolic adversities in patients with schizophrenia. Prog. Neuropsychopharmacol. Biol. Psychiatry 35, 1927-1932. doi: 10.1016/j.pnpbp.2011.07.014

Chintoh, A. F., Mann, S. W., Lam, L., Giacca, A., Fletcher, P., Nobrega, J., et al. (2009). Insulin resistance and secretion in vivo: effects of different antipsychotics in an animal model. Schizophr. Res. 108, 127-133. doi: 10.1016/j.schres.2008.12.012

Cho, H., Mu, J., Kim, J. K., Thorvaldsen, J. L., Chu, Q., Crenshaw, E. B., et al. (2001). Insulin resistance and a diabetes mellitus-like syndrome in mice lacking the protein kinase Akt2 (PKB $)$. Science 292, 1728-1731. doi: $10.1126 /$ science.292.5522.1728

Citrome, L., Collins, J., Nordstrom, B., Rosen, E., Baker, R., Nadkarni, A., et al. (2013). Incidence of cardiovascular outcomes and diabetes mellitus among users of second-generation antipsychotics. J. Clin. Psychiatry 74, 1199-1206. doi: 10.4088/JCP.13m08642

Coccurello, R., Brina, D., Caprioli, A., Conti, R., Ghirardi, O., Schepis, F., et al. (2009). 30 days of continuous olanzapine infusion determines energy imbalance, glucose intolerance, insulin resistance, and dyslipidemia in mice. J. Clin. Psychopharmacol. 29, 576-583. doi: 10.1097/JCP.0b013e3181bfe13e

Contreras-Shannon, V., Heart, D. L., Paredes, R. M., Navaira, E., Catano, G., Maffi, S. K., et al. (2013). Clozapine-induced mitochondria alterations and inflammation in brain and insulin-responsive cells. PLOS ONE 8:e59012. doi: 10.1371/journal.pone.0059012

Cooper, G. D., Harrold, J. A., Halford, J. C. G., and Goudie, A. J. (2008). Chronic clozapine treatment in female rats does not induce weight gain or metabolic abnormalities but enhances adiposity: implications for animal models of antipsychotic-induced weight gain. Prog. Neuropsychopharmacol. Biol. Psychiatry 32, 428-436. doi: 10.1016/j.pnpbp.2007.09.012

Cope, M. B., Li, X., Jumbo-Lucioni, P., DiCostanzo, C. A., Jamison, W. G., Kesterson, R. A., et al. (2009). Risperidone alters food intake, core body temperature, and locomotor activity in mice. Physiol. Behav. 96, 457-463. doi: 10.1016/j.physbeh.2008.11.011

Correll, C. U. (2010). From receptor pharmacology to improved outcomes: individualising the selection, dosing, and switching of antipsychotics. Eur. Psychiatry 25(Suppl. 2), S12-S21. doi: 10.1016/S0924-9338(10)71701-6

Davey, K., Cotter, P., O'Sullivan, O., Crispie, F., Dinan, T., Cryan, J., et al. (2013). Antipsychotics and the gut microbiome: olanzapine-induced metabolic dysfunction is attenuated by antibiotic administration in the rat. Transl. Psychiatry 3:e309. doi: 10.1038/tp.2013.83

De Hert, M., Detraux, J., van Winkel, R., Yu, W., and Correll, C. U. (2012). Metabolic and cardiovascular adverse effects associated with antipsychotic drugs. Nat. Rev. Endocrinol. 8, 114-126. doi: 10.1038/nrendo.2011.156

Deng, C. (2013). Effects of antipsychotic medications on appetite, weight, and insulin resistance. Endocrinol. Metab. Clin. North Am. 42, 545-563. doi: 10.1016/j.ecl.2013.05.006

Deng, C., Lian, J. M., Pai, N., and Huang, X. F. (2012). Reducing olanzapineinduced weight gain side effect by using betahistine: a study in the rat model. $J$. Psychopharmacol. 26, 1271-1279. doi: 10.1177/0269881112449396

Deng, C., Weston-Green, K., and Huang, X.-F. (2010). The role of histaminergic $\mathrm{H} 1$ and $\mathrm{H} 3$ receptors in food intake: a mechanism for atypical antipsychoticinduced weight gain? Prog. Neuro-Psychopharmacol. Biol. Psychiatry 34, 1-4. doi: 10.1016/j.pnpbp.2009.11.009

Engl, J., Laimer, M., Niederwanger, A., Kranebitter, M., Starzinger, M., Pedrini, M., et al. (2005). Olanzapine impairs glycogen synthesis and insulin signaling in L6 skeletal muscle cells. Mol. Psychiatry 10, 1089-1096. doi: 10.1038/sj.mp.4001729

Fell, M. J., Anjum, N., Dickinson, K., Marshall, K. M., Peltola, L. M., Vickers, S., et al. (2007). The distinct effects of subchronic antipsychotic drug treatment on macronutrient selection, body weight, adiposity, and metabolism in female rats. Psychopharmacology 194, 221-231. doi: 10.1007/s00213-007-0833-9

Ferno, J., Ersland, K. M., Duus, I. H., Gonzalez-Garcia, I., Fossan, K. O., Berge, R. K., et al. (2015). Olanzapine depot exposure in male rats: dose-dependent lipogenic effects without concomitant weight gain. Eur. Neuropsychopharmacol. 25, 923-932. doi: 10.1016/j.euroneuro.2015.03.002

Ferno, J., Varela, L., Skrede, S., Vazquez, M. J., Nogueiras, R., Dieguez, C., et al. (2011). Olanzapine-induced hyperphagia and weight gain associate with orexigenic hypothalamic neuropeptide signaling without concomitant AMPK phosphorylation. PLoS ONE 6:e20571. doi: 10.1371/journal.pone.0020571

Fleischhacker, W. W., Siu, C. O., Bodén, R., Pappadopulos, E., Karayal, O. N., and Kahn, R. S. (2013). Metabolic risk factors in first-episode schizophrenia: baseline prevalence and course analysed from the European First-Episode Schizophrenia Trial. Int. J. Neuropsychopharmacol. 16, 987-995. doi: $10.1017 /$ S1461145712001241

Foley, D. L., and Morley, K. I. (2011). Systematic review of early cardiometabolic outcomes of the first treated episode of psychosis. Arch. Gen. Psychiatry 68, 609-616. doi: 10.1001/archgenpsychiatry.2011.2

Fraguas, D., Correll, C. U., Merchan-Naranjo, J., Rapado-Castro, M., Parellada, M., Moreno, C., et al. (2011). Efficacy and safety of second-generation antipsychotics in children and adolescents with psychotic and bipolar spectrum disorders: comprehensive review of prospective head-to-head and placebo-controlled comparisons. Eur. Neuropsychopharmacol. 21, 621-645. doi: 10.1016/j.euroneuro.2010.07.002

Fröjdö, S., Vidal, H., and Pirola, L. (2009). Alterations of insulin signaling in type 2 diabetes: a review of the current evidence from humans. Biochim. Biophys. Acta 1792, 83-92. doi: 10.1016/j.bbadis.2008.10.019

Fujii, N., Hirshman, M. F., Kane, E. M., Ho, R. C., Peter, L. E., Seifert, M. M., et al. (2005). AMP-activated protein kinase $\alpha 2$ activity is not essential for contraction-and hyperosmolarity-induced glucose transport in skeletal muscle. J. Biol. Chem. 280, 39033-39041. doi: 10.1074/jbc.M504208200 
Ginovart, N., and Kapur, S. (2012). Role of dopamine D(2) receptors for antipsychotic activity. Handb. Exp. Pharmacol. 212, 27-52. doi: 10.1007/978-3-642-25761-2_2

Goodpaster, B. H., and Coen, P. M. (2014). improved mitochondrial function is linked with improved insulin sensitivity through reductions in FFA. Diabetes 63, 2611-2612. doi: 10.2337/db14-0277

Guenette, M. D., Giacca, A., Hahn, M., Teo, C., Lam, L., Chintoh, A., et al. (2013). Atypical antipsychotics and effects of adrenergic and serotonergic receptor binding on insulin secretion in vivo: an animal model. Schizophr. Res. 146, 162-169. doi: 10.1016/j.schres.2013.02.023

Hahn, M., Chintoh, A., Giacca, A., Xu, L., Lam, L., Mann, S., et al. (2011). Atypical antipsychotics and effects of muscarinic, serotonergic, dopaminergic and histaminergic receptor binding on insulin secretion in vivo: an animal model. Schizophr. Res. 131, 90-95. doi: 10.1016/j.schres.2011.06.004

Hahn, M. K., Wolever, T. M., Arenovich, T., Teo, C., Giacca, A., Powell, V., et al. (2013). Acute effects of single-dose olanzapine on metabolic, endocrine, and inflammatory markers in healthy controls. J. Clin. Psychopharmacol. 33, 740-746. doi: 10.1097/JCP.0b013e31829e8333

Han, M., Deng, C., Burne, T. H., Newell, K. A., and Huang, X.-F. (2008). Short-and long-term effects of antipsychotic drug treatment on weight gain and H1 receptor expression. Psychoneuroendocrinology 33, 569-580. doi: $10.1016 /$ j.psyneuen.2008.01.018

Hanssens, L., van Winkel, R., Wampers, M., Van Eyck, D., Scheen, A., Reginster, J.-Y., et al. (2008). A cross-sectional evaluation of adiponectin plasma levels in patients with schizophrenia and schizoaffective disorder. Schizophr. Res. 106, 308-314. doi: 10.1016/j.schres.2008.09.008

He, M., Deng, C., and Huang, X.-F. (2013). The role of hypothalamic H1 receptor antagonism in antipsychotic-induced weight gain. CNS Drugs 27, 423-434. doi: 10.1007/s40263-013-0062-1

He, M., Zhang, Q., Deng, C., Wang, H., Lian, J., and Huang, X.-F. (2014). Hypothalamic histamine H1 receptor-AMPK signaling time-dependently mediates olanzapine-induced hyperphagia and weight gain in female rats. Psychoneuroendocrinology 42, 153-164. doi: 10.1016/j.psyneuen.2014. 01.018

Huang, X.-F., Han, M., Huang, X., Zavitsanou, K., and Deng, C. (2006). Olanzapine differentially affects 5-HT2Aand2C receptor mRNA expression in the rat brain. Behav. Brain Res. 171, 355-362. doi: 10.1016/j.bbr.2006.03.040

Jassim, G., Skrede, S., Vázquez, M. J., Wergedal, H., Vik-Mo, A. O., Lunder, N., et al. (2012). Acute effects of orexigenic antipsychotic drugs on lipid and carbohydrate metabolism in rat. Psychopharmacology 219, 783-794. doi: 10.1007/s00213-011-2397-y

Ji, B., La, Y., Gao, L., Zhu, H., Tian, N., Zhang, M., et al. (2009). A comparative proteomics analysis of rat mitochondria from the cerebral cortex and hippocampus in response to antipsychotic medications. J. Proteome Res. 8, 3633-3641. doi: 10.1021/pr800876z

Jiang, Z. Y., Zhou, Q. L., Coleman, K. A., Boese, Q., and Czech, M. P. (2003). Insulin signaling through Akt/protein kinase B analyzed by small interfering RNA-mediated gene silencing. Proc. Natl. Acad. Sci. U.S.A. 100, 7569-7574. doi: 10.1073/pnas.1332633100

Jin, H., Meyer, J. M., Mudaliar, S., and Jeste, D. V. (2008). Impact of atypical antipsychotic therapy on leptin, ghrelin, and adiponectin. Schizophr. Res. 100, 70-85. doi: 10.1016/j.schres.2007.11.026

Johnson, D. E., Yamazaki, H., Ward, K. M., Schmidt, A. W., Lebel, W. S., Treadway, J. L., et al. (2005). Inhibitory effects of antipsychotics on carbachol-enhanced insulin secretion from perifused rat islets role of muscarinic antagonism in antipsychotic-induced diabetes and hyperglycemia. Diabetes 54, 1552-1558. doi: $10.2337 /$ diabetes.54.5.1552

Kahn, S. E., Cooper, M. E., and Del Prato, S. (2014). Pathophysiology and treatment of type 2 diabetes: perspectives on the past, present, and future. Lancet 383, 1068-1083. doi: 10.1016/S0140-6736(13)62154-6

Kahn, S. E., Hull, R. L., and Utzschneider, K. M. (2006). Mechanisms linking obesity to insulin resistance and type 2 diabetes. Nature 444, 840-846. doi: $10.1038 /$ nature 05482

Kim, S. F., Huang, A. S., Snowman, A. M., Teuscher, C., and Snyder, S. H. (2007). Antipsychotic drug-induced weight gain mediated by histamine $\mathrm{H} 1$ receptorlinked activation of hypothalamic AMP-kinase. Proc. Natl. Acad. Sci. U.S.A. 104, 3456-3459. doi: 10.1073/pnas.0611417104
Kim, Y.-B., Peroni, O. D., Franke, T. F., and Kahn, B. B. (2000). Divergent regulation of Akt1 and Akt2 isoforms in insulin target tissues of obese Zucker rats. Diabetes 49, 847-856. doi: 10.2337/diabetes.49.5.847

Kirk, S. L., Glazebrook, J., Grayson, B., Neill, J. C., and Reynolds, G. P. (2009). Olanzapine-induced weight gain in the rat: role of 5-HT2C and histamine H1 receptors. Psychopharmacology 207, 119-125. doi: 10.1007/s00213-009-1639-8

Klemettila, J.-P., Kampman, O., Seppala, N., Viikki, M., Hamalainen, M., Moilanen, E., et al. (2014). Cytokine and adipokine alterations in patients with schizophrenia treated with clozapine. Psychiatry Res. 218, 277-283. doi: 10.1016/j.psychres.2014.04.049

Kwak, H.-B. (2013). Exercise and obesity-induced insulin resistance in skeletal muscle. Integr. Med. Res. 2, 131-138. doi: 10.1016/j.imr.2013.09.004

Lam, D. D., Garfield, A. S., Marston, O. J., Shaw, J., and Heisler, L. K. (2010). Brain serotonin system in the coordination of food intake and body weight. Pharmacol. Biochem. Behav. 97, 84-91. doi: 10.1016/j.pbb.2010.09.003

Lam, D. D., Przydzial, M. J., Ridley, S. H., Yeo, G. S., Rochford, J. J., O’Rahilly, S., et al. (2008). Serotonin 5-HT2C receptor agonist promotes hypophagia via downstream activation of melanocortin 4 receptors. Endocrinology 149, 1323-1328. doi: 10.1210/en.2007-1321

Larsen, J. R., Vedtofte, L., Jakobsen, M. L., Jespersen, H. R., Jakobsen, M. I., Svensson, C. K., et al. (2017). Effect of liraglutide treatment on prediabetes and overweight or obesity in clozapine- or olanzapine-treated patients with schizophrenia spectrum disorder: a randomized clinical trial. JAMA Psychiatry 74, 719-728. doi: 10.1001/jamapsychiatry.2017.1220

Leucht, S., Cipriani, A., Spineli, L., Mavridis, D., Orey, D., Richter, F., et al. (2013). Comparative efficacy and tolerability of 15 antipsychotic drugs in schizophrenia: a multiple-treatments meta-analysis. Lancet 382, 951-962. doi: 10.1016/S0140-6736(13)60733-3

Leucht, S., Corves, C., Arbter, D., Engel, R. R., Li, C., and Davis, J. M. (2009). Second-generation versus first-generation antipsychotic drugs for schizophrenia: a meta-analysis. Lancet 373, 31-41. doi: 10.1016/S0140-6736(08)61764-X

Lewis, S. W., Barnes, T. R., Davies, L., Murray, R. M., Dunn, G., Hayhurst, K. P., et al. (2006). Randomized controlled trial of effect of prescription of clozapine versus other second-generation antipsychotic drugs in resistant schizophrenia. Schizophr. Bull. 32, 715-723. doi: 10.1093/schbul/sbj067

Lian, J., De Santis, M., He, M., and Deng, C. (2015). Risperidone-induced weight gain and reduced locomotor activity in juvenile female rats: the role of histaminergic and NPY pathways. Pharmacol. Res. 95-96, 20-26. doi: 10.1016/j.phrs.2015.03.004

Lian, J., Huang, X.-F., Pai, N., and Deng, C. (2014a). Betahistine ameliorates olanzapine-induced weight gain through modulation of histaminergic, NPY and AMPK pathways. Psychoneuroendocrinology 48, 77-86. doi: 10.1016/j.psyneuen.2014.06.010

Lian, J., Huang, X.-F., Pai, N., and Deng, C. (2014b). preventing olanzapine-induced weight gain using betahistine: a study in a rat model with chronic olanzapine treatment. PLoS ONE 9:e104160. doi: 10.1371/journal.pone.0104160

Lian, J., Huang, X.-F., Pai, N., and Deng, C. (2016). Ameliorating antipsychoticinduced weight gain by betahistine: mechanisms and clinical implications. Pharmacol. Res. 106, 51-63. doi: 10.1016/j.phrs.2016.02.011

Lin, S.-T., Chen, C.-C., Tsang, H.-Y., Lee, C.-S., Yang, P., Cheng, K.-D., et al. (2014). Association between antipsychotic use and risk of acute myocardial infarction: a nationwide case-crossover study. Circulation 130, 235-243. doi: 10.1161/CIRCULATIONAHA.114.008779.

Lipscombe, L. L., Austin, P. C., Alessi-Severini, S., Blackburn, D. F., Blais, L., Bresee, L., et al. (2014). Atypical antipsychotics and hyperglycemic emergencies: multicentre, retrospective cohort study of administrative data. Schizophr. Res. 154, 54-60. doi: 10.1016/j.schres.2014.01.043

Liu, X., Lian, J., Hu, C.-H., and Deng, C. (2015). Betahistine co-treatment ameliorates dyslipidemia induced by chronic olanzapine treatment in rats through modulation of hepatic AMPK $\alpha$-SREBP-1 and PPAR $\alpha$-dependent pathways. Pharmacol. Res. 100, 36-46. doi: 10.1016/j.phrs.2015.07.023

Liu, X., Wu, Z., Lian, J., Hu, C.-H., Huang, X.-F., and Deng, C. (2017). Timedependent changes and potential mechanisms of glucose-lipid metabolic disorders associated with chronic clozapine or olanzapine treatment in rats. Sci. Rep. 7:2762. doi: 10.1038/s41598-017-02884-w 
Lord, C. C., Wyler, S. C., Wan, R., Castorena, C. M., Ahmed, N., Mathew, D., et al. (2017). The atypical antipsychotic olanzapine causes weight gain by targeting serotonin receptor 2C. J. Clin. Invest. 127, 3402-3406. doi: 10.1172/ JCI93362

Maayan, L., and Correll, C. U. (2011). Weight gain and metabolic risks associated with antipsychotic medications in children and adolescents. J. Child Adolesc. Psychopharmacol. 21, 517-535. doi: 10.1089/cap.2011.0015

Maayan, L., Vakhrusheva, J., and Correll, C. U. (2010). effectiveness of medications used to attenuate antipsychotic-related weight gain and metabolic abnormalities: a systematic review and meta-analysis. Neuropsychopharmacology 35, 1520-1530. doi: 10.1038/npp.2010.21

Malin, S. K., Rynders, C. A., Weltman, J. Y., Barrett, E. J., and Weltman, A. (2016). Exercise intensity modulates glucose-stimulated insulin secretion when adjusted for adipose, liver and skeletal muscle insulin resistance. PLoS ONE 11:e0154063. doi: 10.1371/journal.pone.0154063

Manu, P., Correll, C. U., van Winkel, R., Wampers, M., and De Hert, M. (2012). Prediabetes in patients treated with antipsychotic drugs. J. Clin. Psychiatry 73, 460-466. doi: 10.4088/JCP.10m06822

Martins, P. J. F., Haas, M., and Obici, S. (2010). Central nervous system delivery of the antipsychotic olanzapine induces hepatic insulin resistance. Diabetes 59, 2418-2425. doi: 10.2337/db10-0449

Matsui-Sakata, A., Ohtani, H., and Sawada, Y. (2005). Receptor occupancy-based analysis of the contributions of various receptors to antipsychotics-induced weight gain and diabetes mellitus. Drug Metab. Pharmacokinet. 20, 368-378. doi: $10.2133 / \mathrm{dmpk} .20 .368$

Meghana, K., Sanjeev, G., and Ramesh, B. (2007). Curcumin prevents streptozotocin-induced islet damage by scavenging free radicals: a prophylactic and protective role. Eur. J. Pharmacol. 577, 183-191. doi: 10.1016/j.ejphar.2007.09.002

Memarzia, J., Tracy, D., and Giaroli, G. (2014). The use of antipsychotics in preschoolers: a veto or a sensible last option? J. Psychopharmacol. 28, 303-319. doi: 10.1177/0269881113519506

Minet-Ringuet, J., Even, P. C., Goubern, M., Tome, D., and de Beaurepaire, R. (2006). Long term treatment with olanzapine mixed with the food in male rats induces body fat deposition with no increase in body weight and no thermogenic alteration. Appetite 46, 254-262. doi: 10.1016/j.appet.2006.01.008

Murashita, M., Inoue, T., Kusumi, I., Nakagawa, S., Itoh, K., Tanaka, T., et al. (2007). Glucose and lipid metabolism of long-term risperidone monotherapy in patients with schizophrenia. Psychiatry Clin. Neurosci. 61, 54-58. doi: 10.1111/j.1440-1819.2007.01610.x

Nasrallah, H. (2008). Atypical antipsychotic-induced metabolic side effects: insights from receptor-binding profiles. Mol. Psychiatry 13, 27-35. doi: $10.1038 /$ sj.mp.4002066

Nieto-Vazquez, I., Fernández-Veledo, S., Krämer, D. K., Vila-Bedmar, R., Garcia-Guerra, L., and Lorenzo, M. (2008). Insulin resistance associated to obesity: the link TNF-alpha. Arch. Physiol. Biochem. 114, 183-194. doi: 10.1080/13813450802181047

Oriot, P., Feys, J. L., Mertens de Wilmars, S., Misson, A., Ayache, L., Fagnart, O., et al. (2008). Insulin sensitivity, adjusted beta-cell function and adiponectinaemia among lean drug-naive schizophrenic patients treated with atypical antipsychotic drugs: a nine-month prospective study. Diabetes Metab. 34, 490-496. doi: 10.1016/j.diabet.2008.03.003

Ozasa, R., Okada, T., Nadanaka, S., Nagamine, T., Zyryanova, A., Harding, H., et al. (2013). The antipsychotic olanzapine induces apoptosis in insulin-secreting pancreatic $\beta$ cells by blocking PERK-mediated translational attenuation. Cell Struct. Funct. 38, 183-195. doi: 10.1247/csf.13012

Pai, N., Deng, C., Vella, S.-L., Castle, D., and Huang, X.-F. (2012). Are there different neural mechanisms responsible for three stages of weight gain development in anti-psychotic therapy: temporally based hypothesis. Asian J. Psychiatr. 5, 315-318. doi: 10.1016/j.ajp.2012.05.005

Palsamy, P., and Subramanian, S. (2010). Ameliorative potential of resveratrol on proinflammatory cytokines, hyperglycemia mediated oxidative stress, and pancreatic $\beta$-cell dysfunction in streptozotocin-nicotinamide-induced diabetic rats. J. Cell. Physiol. 224, 423-432. doi: 10.1002/jcp.22138

Panariello, F., Perruolo, G., Cassese, A., Giacco, F., Botta, G., Barbagallo, A. P. M., et al. (2012). clozapine impairs insulin action by up-regulating akt phosphorylation and Ped/Pea-15 protein abundance. J. Cell. Physiol. 227, 1485-1492. doi: 10.1002/jcp.22864
Polcwiartek, C., Vang, T., Bruhn, C. H., Hashemi, N., Rosenzweig, M., and Nielsen, J. (2016). Diabetic ketoacidosis in patients exposed to antipsychotics: a systematic literature review and analysis of Danish adverse drug event reports. Psychopharmacology 233, 3663-3672. doi: 10.1007/s00213-016-4411-x

Poyurovsky, M., Fuchs, C., Pashinian, A., Levi, A., Weizman, R., and Weizman, A. (2013). Reducing antipsychotic-induced weight gain in schizophrenia: a double-blind placebo-controlled study of reboxetine-betahistine combination. Psychopharmacology 226, 615-622. doi: 10.1007/s00213-012-2935-2

Pramyothin, P., and Khaodhiar, L. (2015). Type 2 diabetes in children and adolescents on atypical antipsychotics. Curr. Diab. Rep. 15:53. doi: 10.1007/s11892-015-0623-4

Reed, R. M., Graham, K. A., Rau, S. W., Gilmore, J. H., Perkins, D. O., Peebles, S. S., et al. (2014). A naturalistic comparison of the longterm metabolic adverse effects of clozapine versus other antipsychotics for patients with psychotic illnesses. J. Clin. Psychopharmacol. 34, 441-445. doi: 10.1097/JCP.0000000000000159

Rondinone, C., Carvalho, E., Wesslau, C., and Smith, U. (1999). Impaired glucose transport and protein kinase B activation by insulin, but not okadaic acid, in adipocytes from subjects with Type II diabetes mellitus. Diabetologia 42, 819-825. doi: 10.1007/s001250051232

Rubí, B., Ljubicic, S., Pournourmohammadi, S., Carobbio, S., Armanet, M., Bartley, C., et al. (2005). Dopamine D2-like receptors are expressed in pancreatic beta cells and mediate inhibition of insulin secretion. J. Biol. Chem. 280, 36824-36832. doi: 10.1074/jbc.M505560200

Samara, M. T., Dold, M., Gianatsi, M., Nikolakopoulou, A., Helfer, B., Salanti, G., et al. (2016). Efficacy, acceptability, and tolerability of antipsychotics in treatment-resistant schizophrenia: a network meta-analysis. JAMA Psychiatry 73, 199-210. doi: 10.1001/jamapsychiatry.2015.2955

Samaras, K., Correll, C. U., Mitchell, A. J., De Hert, M., and HeAL Collaborators Healthy Active Lives for People With Severe Mental Illness (2014). Diabetes risk potentially underestimated in youth and children receiving antipsychotics. JAMA Psychiatry 71, 209-210. doi: 10.1001/jamapsychiatry.2013.4030

Seeman, M. V. (2009). Secondary effects of antipsychotics: women at greater risk than men. Schizophr. Bull. 35, 937-948. doi: 10.1093/schbul/sbn023

Seino, S. (2012). Cell signalling in insulin secretion: the molecular targets of ATP, cAMP and sulfonylurea. Diabetologia 55, 2096-2108. doi: 10.1007/s00125-012-2562-9

Shin, S. Y., Choi, B. H., Ko, J., Kim, S. H., Kim, Y. S., and Lee, Y. H. (2006). Clozapine, a neuroleptic agent, inhibits Akt by counteracting $\mathrm{Ca}^{2+}$ calmodulin in PTEN-negative U-87MG human glioblastoma cells. Cell. Signal. 18, 1876-1886. doi: 10.1016/j.cellsig.2006.02.004

Shirakawa, J., and Kulkarni, R. N. (2016). Novel factors modulating human beta-cell proliferation. Diabetes Obes. Metab. 18(Suppl. 1), 71-77. doi: $10.1111 /$ dom. 12731

Silvestre, J. S., and Prous, J. (2005). Research on adverse drug events. I. Muscarinic M3 receptor binding affinity could predict the risk of antipsychotics to induce type 2 diabetes. Methods Findi. Exp. Clin. Pharmacol. 27, 289-304. doi: 10.1358/mf.2005.27.5.908643

Skrede, S., Martins, L., Berge, R. K., Steen, V. M., López, M., and Fernø, J. (2014). Olanzapine depot formulation in rat: a step forward in modelling antipsychotic-induced metabolic adverse effects. Int. J. Neuropsychopharmacol. 17, 91-104. doi: 10.1017/S1461145713000862

Sohn, M., Talbert, J., Blumenschein, K., and Moga, D. C. (2015). Atypical antipsychotic initiation and the risk of type II diabetes in children and adolescents. Pharmacoepidemiol. Drug Saf. 24, 583-591. doi: 10.1002/pds.3768

Stahl, S. (2003). Describing an atypical antipsychotic: receptor binding and its role in pathophysiology. Primary Care Companion J. Clin. Psychiatry 5(Suppl 3), 9-13.

Stefanidis, A., Verty, A. N. A., Allen, A. M., Owens, N. C., Cowley, M. A., and Oldfield, B. J. (2009). The role of thermogenesis in antipsychotic drug-induced weight gain. Obesity 17, 16-24. doi: 10.1038/oby.2008.468

Steinhausen, H.-C. (2015). Recent international trends in psychotropic medication prescriptions for children and adolescents. Eur. Child Adolesc. Psychiatry 24, 635-640. doi: 10.1007/s00787-014-0631-y

Stubbs, B., Vancampfort, D., De Hert, M., and Mitchell, A. J. (2015). The prevalence and predictors of type two diabetes mellitus in people with schizophrenia: a systematic review and comparative meta-analysis. Acta Psychiatr. Scand. 132, 144-157 doi: 10.1111/acps.12439 
Su, H.-C., Hung, L.-M., and Chen, J.-K. (2006). Resveratrol, a red wine antioxidant, possesses an insulin-like effect in streptozotocin-induced diabetic rats. Am. J. Physiol. Endocrinol. Metab. 290, E1339-E1346. doi: 10.1152/ajpendo.00487.2005

Sugai, T., Suzuki, Y., Fukui, N., Ono, S., Watanabe, J., Tsuneyama, N., et al. (2012), Dysregulation of adipocytokines related to second-generation antipsychotics in normal fasting glucose patients with schizophrenia. J. Clin. Psychopharmacol. 32, 390-393. doi: 10.1097/JCP.0b013e3182524393

Teff, K. L., Rickels, M. R., Grudziak, J., Fuller, C., Nguyen, H.-L., and Rickels, K. (2013). Antipsychotic-induced insulin resistance and postprandial hormonal dysregulation independent of weight gain or psychiatric disease. Diabetes 62, 3232-3240. doi: 10.2337/db13-0430

Tremblay, F., Lavigne, C., Jacques, H., and Marette, A. (2001). Defective insulin-induced GLUT4 translocation in skeletal muscle of high fatfed rats is associated with alterations in both Akt/protein kinase B and atypical protein kinase, C. $(\zeta / \lambda)$ activities. Diabetes 50, 1901-1910. doi: $10.2337 /$ diabetes.50.8.1901

Turnbaugh, P. J., Hamady, M., Yatsunenko, T., Cantarel, B. L., Duncan, A., Ley, R. E., et al. (2009). A core gut microbiome in obese and lean twins. Nature 457, 480-484. doi: 10.1038/nature07540

Uysal, K. T., Wiesbrock, S. M., Marino, M. W., and Hotamisligil, G. S. (1997). Protection from obesity-induced insulin resistance in mice lacking TNF- $\alpha$ function. Nature 389, 610-614. doi: 10.1038/39335

van der Zwaal, E. M., Janhunen, S. K., la Fleur, S. E., and Adan, R. A. H. (2014). Modelling olanzapine-induced weight gain in rats. Int. J. Neuropsychopharmacol. 17, 169-186. doi: 10.1017/S1461145713 00093X.

van der Zwaal, E. M., Merkestein, M., Lam, Y. K., Brans, M. A. D., Luijendijk, M. C. M., Bok, L. I. H., et al. (2012). The acute effects of olanzapine on ghrelin secretion, CCK sensitivity, meal size, locomotor activity and body temperature. Int. J. Obes. 36, 254-261. doi: 10.1038/ijo.2011.97

van Winkel, R., De Hert, M., Wampers, M., Van Eyck, D., Hanssens, L., Scheen, A., et al. (2008). Major changes in glucose metabolism, including new-onset diabetes, within 3 months after initiation of or switch to atypical antipsychotic medication in patients with schizophrenia and schizoaffective disorder. J. Clin. Psychiatry 69, 472-479. doi: 10.4088/JCP.v69n0320

Verma, S., and Hussain, M. E. (2017). Obesity and diabetes: an update. Diab. Metab. Syndrome. Clin. Res. Rev. 11, 73-79. doi: 10.1016/j.dsx.2016. 06.017

Victoriano, M., de Beaurepaire, R., Naour, N., Guerre-Millo, M., QuignardBoulangé, A., Huneau, J.-F., et al. (2010). Olanzapine-induced accumulation of adipose tissue is associated with an inflammatory state. Brain Res. 1350, 167-175. doi: 10.1016/j.brainres.2010.05.060

von Wilmsdorff, M., Bouvier, M. L., Henning, U., Schmitt, A., SchneiderAxmann, T., and Gaebel, W. (2013). The Sex-dependent impact of chronic clozapine and haloperidol treatment on characteristics of the metabolic syndrome in a rat model. Pharmacopsychiatry 46, 1-9. doi: 10.1055/s-0032-13 21907

Wampers, M., Hanssens, L., van Winkel, R., Heald, A., Collette, J., Peuskens, J., et al. (2012). Differential effects of olanzapine and risperidone on plasma adiponectin levels over time: results from a 3-month prospective open-label study. Eur. Neuropsychopharmacol. 22, 17-26. doi: 10.1016/j.euroneuro.2011.03.010

Weir, G. C., and Bonner-Weir, S. (2004). Five stages of evolving betacell dysfunction during progression to diabetes. Diabetes 53, S16-S21. doi: 10.2337/diabetes.53.suppl_3.S16

Weston-Green, K., Huang, X.-F., and Deng, C. (2010). Sensitivity of the female rat to olanzapine-induced weight gain-Far from the clinic? Schizophr. Res. 116, 299-300. doi: 10.1016/j.schres.2009.09.034
Weston-Green, K., Huang, X.-F., and Deng, C. (2011). Olanzapine treatment and metabolic dysfunction: a dose response study in female Sprague Dawley rats. Behav. Brain Res. 217, 337-346. doi: 10.1016/j.bbr.2010.10.039

Weston-Green, K., Huang, X.-F., and Deng, C. (2012a). Alterations to melanocortinergic, GABAergic and cannabinoid neurotransmission associated with olanzapine-induced weight gain. PLoS ONE 7:e33548. doi: 10.1371/journal.pone.0033548

Weston-Green, K., Huang, X.-F., and Deng, C. (2013). Second generation antipsychotic-induced type 2 diabetes: a role for the muscarinic M3 receptor. CNS Drugs 27, 1069-1080. doi: 10.1007/s40263-013-0115-5

Weston-Green, K., Huang, X.-F., Lian, J., and Deng, C. (2012b). Effects of olanzapine on muscarinic M3 receptor binding density in the brain relates to weight gain, plasma insulin and metabolic hormone levels. Eur. Neuropsychopharmacol. 22, 364-373. doi: 10.1016/j.euroneuro.2011.09.003

Wilding, J. (2007). The importance of free fatty acids in the development of Type 2 diabetes. Diab. Med. 24, 934-945. doi: 10.1111/j.1464-5491.2007.02186.x

Wu, C. S., Tsai, Y. T., and Tsai, H. J. (2015). Antipsychotic drugs and the risk of ventricular arrhythmia and/or sudden cardiac death: a nation-wide casecrossover study. J. Am. Heart Assoc. 4:e001568. doi: 10.1161/JAHA.114.001568

Wu, R.-R., Zhao, J.-P., Zhai, J.-G., Guo, X.-F., and Guo, W.-B. (2007). Sex difference in effects of typical and atypical antipsychotics on glucose-insulin homeostasis and lipid metabolism in first-episode schizophrenia. J. Clin. Psychopharmacol. 27, 374-379. doi: 10.1097/JCP.0b013e3180cac8db

Xiao, X., Gaffar, I., Guo, P., Wiersch, J., Fischbach, S., Peirish, L., et al. (2014). M2 macrophages promote beta-cell proliferation by up-regulation of SMAD7. Proc. Natl. Acad. Sci. U.S.A. 111, E1211-E1220. doi: 10.1073/pnas.1321347111

Zhang, J.-P., Gallego, J. A., Robinson, D. G., Malhotra, A. K., Kane, J. M., and Correll, C. U. (2013). Efficacy and safety of individual second-generation vs. first-generation antipsychotics in first-episode psychosis: a systematic review and meta-analysis. Int. J. Neuropsychopharmacol. 16, 1205-1218. doi: $10.1017 /$ S1461145712001277

Zhang, Q., Deng, C., and Huang, X.-F. (2013). The role of ghrelin signalling in second-generation antipsychotic-induced weight gain. Psychoneuroendocrinology 38, 2423-2438. doi: 10.1016/j.psyneuen.2013.07.010

Zhang, Q., He, M., Deng, C., Wang, H., Lian, J., and Huang, X.-F. (2014a). Hypothalamic ghrelin signalling mediates olanzapine-induced hyperphagia and weight gain in female rats. Int. J. Neuropsychopharmacol. 17, 807-818. doi: $10.1017 /$ S1461145713001697

Zhang, Q., Lian, J., He, M., Deng, C., Wang, H., and Huang, X.-F. (2014b). Olanzapine reduced brown adipose tissue thermogenesis and locomotor activity in female rats. Prog. Neuropsychopharmacol. Biol. Psychiatry 51, 172-180. doi: 10.1016/j.pnpbp.2014.02.003

Zipursky, R. B., Gu, H., Green, A. I., Perkins, D. O., Tohen, M. F., McEvoy, J. P., et al. (2005). Course and predictors of weight gain in people with first-episode psychosis treated with olanzapine or haloperidol. Br. J. Psychiatry 187, 537-543. doi: 10.1192/bjp.187.6.537

Conflict of Interest Statement: The authors declare that the research was conducted in the absence of any commercial or financial relationships that could be construed as a potential conflict of interest.

The reviewer IG-G and handling Editor declared their shared affiliation.

Copyright (c) 2017 Chen, Huang, Shao, Chen and Deng. This is an open-access article distributed under the terms of the Creative Commons Attribution License (CC BY). The use, distribution or reproduction in other forums is permitted, provided the original author(s) or licensor are credited and that the original publication in this journal is cited, in accordance with accepted academic practice. No use, distribution or reproduction is permitted which does not comply with these terms. 